\title{
AN OVERVIEW OF POST WAR SOCIAL PROBLEMS IN SYRIA
}

\author{
* Dr. Maryam Bibi, Jinnah University for Women, Karachi - Pakistan \\ **Eraj Saleem, Jinnah University for Women, Karachi - Pakistan \\ ***Shafaq Zahid, Jinnah University for Women, Karachi - Pakistan
}

\begin{abstract}
:
Addiction is a disease that alters the behaving and thinking of the brain of a person. When a person starts using drugs, it starts getting addicted to them and gradually it can't help but act on the impulse to use them regardless of the damage caused to the body of addicted person. Drug isn't about just illegal drugs. A person can get addicted to alcohol, painkillers, nicotine and other legal substances. Drug addiction is a deathly disease found in almost every year of age. The disease is mostly carried by people who are mentally frustrated, physically or mentally abused, facing financial problem or family problems and is desperate to get some sort of relief that comes with the high of drugs even if it proves to be grim for their health in the long run. Addiction starts with the continuous use of dosage of any drug, until the point that an individual starts feeling anxious without the availability of them. Slowly and painfully, these drugs starts making a person totally relied on them and it is basically impossible for the individual to survive without them. There can be many reasons as to why an individual decides to go on this path of addiction. Economic problems, state of utter sadness in case of the death of a loved one or a closed one, societal stress, isolation, aggression, bad or wrong company, in state of depression and anxiety are the most likely situations in which a person starts taking drugs. Along with many other factors, families often play a vital role in pushing an individual towards seeking comfort and relief from the drugs. Developing countries like Pakistan and many others are facing the problem as there are not many effective and active rehabilitation centers. In this research article, the role of families contributing in an individual's drug addiction is elaborated. This research article is done with the help of many researches, as well as some interviews were conducted regarding certain factors and the answers were given according to the observation and views of responders. The conclusion is drawn with the help of articles and personal opinions and observations regarding how a person leans toward substance or drug usage because of certain family issues and problems.
\end{abstract}

\section{Keywords: Syria, Families Problems, Drugs, Children.}




\section{INTRODUCTION:}

Addiction is defined as a chronic, the physical disorder of a human being, deteriorating disorder characterized by uncontrollable use of drugs, relentless use despite the detrimental repercussions, and deep rooting damages in the human body and that leaves a harmful and long lasting effect on the human body. (Miller, 2002) Drug addiction mostly starts with the experimental and amusing use of a drug in social gatherings, and, for some people, the drug usage gets persistent. For others, majorly in the case of usage of opioids, the addiction begins with manifestation to directed medications, or receiving medications from a friend or relative who has been prescribed the medication. The chances of getting addicted and in how much time one gets addicted to a drug, varies by drug. Some drugs, such as opioid painkillers, cause addiction more quickly compared to others. gradually, one may need higher dosage of the drug to get stoned. Soon the person starts craving drugs just to feel happy and content. As the drug use increases, the individual finds that it's getting impossible to go without the drug. (Sheff, 2019) The effects of drugs on the body may appear like, Stroke, mental confusion, brain damage, lung disease, problems with memory, attention and decisions. Physical abnormalities such as breast development in men and increase in body temperature which can affect human body health are mostly seen in those who take severe amount of drugs. (The Global Initiative against Transnational Organized Crime, 2016) Certain factors like, physical and sexual abuse, early exposure to drugs can lead a person to drug addiction. Stress is the common factor of drug addictions nowadays. In this factors the measure role of family because of isolation of their child not doing attention of their child if family don't understand their children problems and they become alone and isolated and they started drug like smoking, sheesha, alcohol and etc.. The parental guidance can greatly affect a person's likelihood of drug use and drugs addictions. (Lalevee, 1985)

PRODUCTION, ABUSE AND SMUGGLING DRUGS SPREADING IN SYRIA 
The land under the control of authorities is not the only breeding place of drugs, as it has now spread all over the cities and towns of Syria. The war drastically proved to be in favor of drug traffickers, and actually gave the drug users more pretexts and engross in the habit more and more. Due to its geographical location, Syria is globally considered a drug-transit country .drug use and addiction among children living in Syria very high levels as footage of children under the influence has been circulating on social media recently.one of the main reasons behind this rise in drug use among children is the sociological factors caused by the eight-year civil war. Forcing children to use drugs in order to turn them into loyal beings that work as beggars in the street is another common factor that has caused the addiction problem to reach such levels. (Marshall, 2012) A corruption case rocked the Interior Ministry in Damascus last week and prompted Interior Minister investigations with Maj. Gen. Raed Khazim, Director of the Anti-Narcotics Department, and a number of officers, have revealed their involvement in replacing narcotics with non-narcotics to clear drug traffickers and criminals, following the seizure of 83 kilograms of cocaine. According to unofficial Syrian media close to the regime, investigations showed the involvement of officers of the interior ministry in overseeing the cultivation of cannabis in secret places. They were detained in Adra central prison pending investigation.

Syrian cannabis trade has been active during the war. Media activists in the opposition accuse the militias of the Lebanese Hezbollah and the military security branch of smuggling drugs and cannabis from the Bekaa in Lebanon to Syria through the border areas of The opposition also accuses the regime's militias of promoting narcotics among school students. Drug pills and cannabis are even sold publicly on the streets. They also confirm the involvement of influential regime figures and Hezbollah in promoting drugs in Syria.

Drugs are an important financial resource for Hezbollah, estimated at hundreds of millions Human rights sources following up the case in Damascus told Asharq Al-Awsat that the defendants face corruption charges of more than 4 billion Syrian pounds (6.5 million dollars), worth 83 kilograms of cocaine, which were confiscated by the Drug Enforcement 
Authority. During their arrest, the cocaine powder was replaced with flour to clear the defendants, who include government officials. (Syria's Drug Control Director Accused of Covering up for Traffickers , 2019)

\section{SIGNS SOMEONE IS ADDICTED.}

Drug addiction symptoms or behaviors include, among others:

- The constant craving to use the drugs daily, once or even more than one time a day, the craving for drug being too fierce that it blocks out any other thought in a person's mind and after some time, entailing higher dosage of the drug to get the craved effect.

- Taking larger amounts of the drug over a longer period of time than you intended.

- Making sure to maintain a sufficient supply of drug.

- Even if it is hard to afford, spending money on drugs.

- Not completing assigned tasks or fulfilling work responsibilities, or avoiding social gatherings or activities because of drug usage.

- Despite knowing that the drugs are causing you physical and psychological harm, you continue to use the drugs.

- Doing certain things to get the drugs that you wouldn't do while being conscious, like stealing.

- Performing activities that can be considered perilous, like driving, while being high.

- Having a hard time while attempting to stop taking the drugs.

\section{SIGNS OF RECENT SUBSTANCE USAGE:}

There are different types of drugs. The symptoms vary according to the type and dosage of drugs. In eastern countries, Hasheesh, opium and cocaine are mostly used by all age groups and genders. While in the western countries, the most used drugs are Marijuana, opium, cocaine and Cannabis. There are certain signs and symptoms that verify or confirm that an individual has recently used drugs or is an addict. 
People use cannabis by smoking, either ingesting or inhaling a striking form of the drug. Cannabis is usually taken prior, or is taken with other drugs, like intoxicants or illegal substances, and is usually the first attempted drug.

Signs and symptoms of recent use can include:

- A feeling of ecstasy or delight and glee.

- Improved sensation of seeing, hearing and tasting.

- Increased blood pressure and heart rate

- Red eyes

- Cottonmouth.

- Decreased coordination

- Struggling in focusing or recalling.

- Slow responding.

- Anxious or overly suspicious thoughts.

- Cannabis stench on clothes or yellowish fingertips.

- In rare times excessive cravings for specific food.

$\bullet$

Persistent (chronic) use is frequently correlated with:

- Reduced mental acuity.

- Bad academic or professional performance.

- Smaller social circle and interests.

\section{RECOGNIZING UNHEALTHY DRUG USE IN FAMILY MEMBERS}

It is occasionally hard to differenciate from signs of medication normal mo od or anxiety among teenagers. Probable signs of drugs being used by you $\mathrm{r}$ teenager or other family member include:

- Problems at school or work - frequently missing school or work, a sudden disinterest in school activities or work, or a drop in grades or work performance 
- Physical health issues - lack of energy and motivation, weight loss or gain, or red eyes

- Neglected appearance - lack of interest in clothing, grooming or looks

- Changes in behavior - exaggerated efforts to bar family members from entering his or her room or being secretive about where he or she goes with friends; or drastic changes in behavior and in relationships with family and friends

- Money issues - sudden requests for money without a reasonable explanation; or your discovery that money is missing or has been stolen or that items have disappeared from your home, indicating maybe they're being sold to support drug use.

\section{STAGING AN INTERVENTION}

Those experiencing alcoholism usually decline to seek medical help, because their substance use is troublesome. Interference portrays a loved one with an organized chance to make improvements before things continue to worsen may motive someone to attempt or receive assistance. An action should be arranged cautiously and can be performed by family and friends or a professional like a certified drug counselor or an intervention professional in consulting with the specialist or professional. This includes parents, friends and often employers, pastors or other people who care about the addicted individual.

\section{PREVENTING DRUG MISUSE IN CHILDREN AND TEENAGERS}

These measures can be taken to control addiction in teenagers and children:

- Communicate. Discuss the possibility of using drugs and abuse wi th your children.

- Listen. Be a good listener while your children tell you about the peer pressure and support their resisting efforts. 


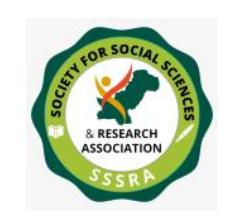

- Set a good example. . Try not to use drugs or drink alcohol in front of your children. Children of addictive parents are more likely at a risk of drug addiction.

\section{DISCUSSION:}

Family plays a vital role in the drug addiction of a person. Most of the times, there's problems and issues from family that lead a person to this venom, also called Drug addiction. The issues or problems from family palpably leave its trauma on a person that it starts searching comfort within drugs. The most common issues being usage of drug in family and family dynamics, poor communication within family, neglecting of druggie parents, financial crisis in family, death of a beloved one, domestic abuse and violence. These problems seem to lead a person to depressing environment and the person starts creating an artificial pleasant environment for itself that comes with the high of drugs. (Drug Addictions) A child learns its socializing pattern by its family. Family is the most basic unit of socialization that passes its perceptions, learning and values to a child intentionally or unintentionally. The family's way of behaving to a situation, its morals and values basically teaches a child how he is supposed to react and leaves indentation in the behavior of child. The positive or negative attitude of family towards substance use may affect the likeliness of drug use in an individual. The individual may lean towards drug use as a result of learning of drug usage as a family pattern or in response to family problems and situations.(Mathew)

The very first problem that seems to steer a person towards an addictive path is the usage of drugs by parents. Parents who use drugs welcome two different faces of problems in their lives, the consequences of using these illegal substances and because of its relapsing condition. Illegality of drug usage by parents might tempt the children to perform criminal activities and exposure of drugs for themselves. On the other hand, parents who use drugs, whether rampant or controlled dosage, result in neglect and abuse of the child. The most common outcome of parental drug usage is the abandonment and domestic violence on the child. Parents, who are addicted to drugs, usually fail to look after their children. They neglect 


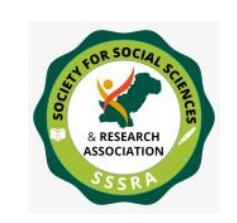

their needs and fail to socialize them. This often result in the child becoming an addict itself as the brought up of that child was abusive and being with a drug addict parent entice the child to be one itself. Secondly, some children lean towards drug addiction because of the genetic take over. According to studies, if one or both parents use drugs, their children are most likely to use drug themselves. A general interview was conducted regarding this ordeal with two individuals. Both of them were subjected to the use of drugs somehow. Answers were given according to their beliefs and observations. When asked what is their opinion on the belief that a child of drug addicted parents is most likely to become a victim of this addiction too, this was their answer. According to the first views of first responder, "children who experience dealing with a druggie and are used to watching an unconscious parent mostly hate the general idea of drugs. Because although their parent is high, but they are observing the situation of their intoxicated parent and the social and mental destruction that comes as a gift with the addiction of these sort of drugs, they are mostly antagonistic towards drug usage. I myself use some of these substances that can be referred as drugs, but I'm certain that my family despise this action despite all their love for me."And according to the views of second responder, "It depends on the family dynamics, if the family is against drug usage, the children might end up hating their parent and their actions. But on the other hand, and what mostly happens is, a child idolizes its parents, so when it sees them using drugs, it is most certain that the child will sometime in the future surely do it too. And most importantly, the thinking of the child is if my parents are doing it, then there must be no harm in it. The subject quoted a famous Urdu saying,' Charsika beta bhiCharsi hi hotahai'. The interview was ended with an example given by the subject," my cousin was generally opposed to the idea of cigarettes, but when eventually growing up he saw his father smoking cigarettes, it spurred something in him and now we see him as a chain smoker." (Barnard, 2006).

The early exposure to drugs is also determined as a factor in an individual becoming drug addict. Moreover, parents are often unaware of their young child's curiosity and tendency of trying drugs at such a young age. For example, according to a 1996 survey by a partnership for Drug-Free 
America, there was a report that stated that $40 \%$ of students from 7 th to 12th grade had tried Marijuana, while only $15 \%$ of their parents actually believed in the fact that their children had tried marijuana. Peer group also play its crucial role in contributing in introducing a child into the world of drugs. According to another report of Drug-Free America survey, 45\% parents thought that their children's peer used drugs, while $69 \%$ of teens proclaimed that their peers used drugs.

In Pakistan, mostly the family dynamics consist of a comparatively lenient and communicating mother while father is considered more of an authoritative figure. Sometimes while keeping up this image, the father usually goes overboard in disciplining their child. They don't hesitate to even physically abuse the child if it acts out. The yelling and severe beatings scar the mind of child and depression and anxiety make a home out of the children's mind. To cope up with this built-up anxiety and stress, mostly teenagers tend to occupy themselves in a world full of fake pleasantries and become a sitting target of drug abuse.On a broader level, mostly mothers are the ones who face difficulty in disciplining their child. They do not have the dominating aura that a father possesses, so they face rather difficulty in castigating the kids. When the mothers fail to discipline their child by their 'stern' talk, the alternative way they use is mostly in form of yelling and beatings. This usually creates a communication gap between the child and parent and the child starts keeping their problems and thoughts to themselves to be safe from any further beating-ups. This often leads the child to be a victim of tension and stress. The child starts looking out for someone outside of the family to share their depressed thoughts and most likely becomes a drug addict either by his choice or bad company influence. The lack of parental guide and assistance is most often the reason an individual gets involved in substance use because of bad company influence.The lack of communication can also be described as another major factor in steering an individual towards drug addiction. Man is a social animal and while socializing, thousands of thoughts penetrate a person's mind which can either pleasant or problematic. Families often neglect the importance of communication. Parents are often up tied in this regard. They do not think it as a necessity to sit down and have some casual chats with their children just for the sake of it and might ask them 


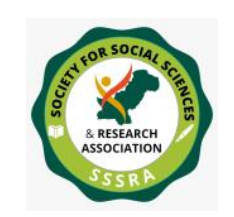

about their problems or any issue Half of the stress can be released with simply just sharing the problem with them with closed ones and family. In the case of such families where there are no practices of sharing and communicating, the individual will try to find some other heart to disclose its miseries; they might get tangled into bad groups who lead them to using drugs as a temporary relief. (Das, et al. 2016)

Lack of social support from the family can also lead to addictive behaviors as a way to deal with the negative emotions and sentiments. Social support is a perception that is required by an individual of every age group. The most effective and intimate social support can be provided only by family. The support and guidance provided in difficult situations have proven to be a shield against the depressing thoughts and anxiety. But if the family fails to provide support, the individual might lose to provide emotional support in critical times, the chances of drug using are likeliest. (Matthew, Regmi, \& Lama, 2018). Family economic status can be conjured as one of the most important reason in forcing an individual in the wrong and abusive direction. Looking on the national level, Pakistani family dynamics mostly consist of joint family system. There are one or two dominant figures that are supposed to provide for the whole family of probably 10 to 12 mouths including the grandparents too. Providing for larger families substantially turns out to be oppressive for the providers as there are more mouths to feed and more bodies to provide clothes for. Not only this, but mostly the grandparents are not completely healthy, they need to be taken care of and providing them healthy food and their medicines might get harsh on the financial position of the family. In these cases, the individual might built up some problems of their own and there might be feasibility of them in steering towards drug addiction as a stress relievers. (Barnard, 2006)

The poor economic status might also result in an individual to become an early provider himself for the family that crucially affects the drug use of a person. A research was conducted among 7 participants. 3 out of 7 participants claimed that the reason of their drug use was the family' poverty. One mentioned the reason was becoming the bread provider for the family while she was still a child, never got the chance to get proper 
education and unfortunately, got mixed with bad company and while struggling for providing for the family, got into drug abusing and trafficking in order to earn money quickly. The other participants also had similar reasons. One claimed that she had to become an early provider for the family too and she started taking drugs as stress relievers. When a question 'what do you think, does families financial status contributes as one of the reason a person gets involved in drug addiction or not?' was asked to an individual, they responded:According to the views of responder, "when a person's family status is financially weak, the person is under a lot of pressure. He needs job, money to buy necessities for daily life, money to pay bills, to feed the mouths that are waiting for him to bring something to eat, all the things basically add up to the availability of money. In Pakistan, it is not really easy to earn money except for begging. The stress that comes with the pressure of money earning is a lot, and the easiest way us Pakistanis think to reduce pressure off our minds is nicotine that is easily available in the form of cigarettes. And when a person starts smoking cigarettes, gradually it is not enough to satisfy his need and allow him the pleasure he is craving for. Then a person becomes chain smoker, starts taking different types of drugs and even sometimes alcohol. Sp yeah definitely the stress which comes with the financial problems is definitely one of the reasons why an individual decides to start taking drugs.I am not telling you a tale or something that is only written in books. This is my personal observation. There was a friend of mine whom father died at a very young age. He was maybe 14 or 15 years old and we were class mates. He had to drop his education and work somewhere to provide for his family. The stress this situation brought upon him was unbearable. The idea that taking drugs would solve all his problems was somehow stuck in his head and he started taking huge amount of drugs. Gradually, the addiction got worse and now he is in some rehabilitation center and working on his recovery." (Foo, Tam, \& Lee, 2012)

The siblings' influence is also a great factor in the drug usage of an individual. When a younger sibling observes their older siblings using substances, there is a higher possibility that they will try using it out of curiosity or simply influence. According to a research, a younger kid gets under influence of parents, peers or older siblings who use drugs but 


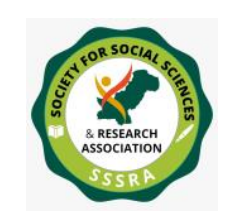

mostly under ascendancy of peers and older siblings using drugs. Sometimes, parents fail to properly look after their kids. They have no tabs on what their child is doing and what type of company he is spending his time with. This neglecting behavior often proves to be disastrous for the families. This is like an open invitation to the drug dealers and addicts out there. The child starts passing its time under bad company. It either starts getting involved in criminal activities or starts taking drugs. (Barnard 2006)

Among all these different reasons, one of the most important reason of a person starting to find comfort in drugs is facing the hardships of life and death of a beloved one or a family member. Adel, aged 30, a native from Harasta, Syria was asked about his addiction of Hashish. He said that he had to support his family of a mother and 5 siblings after his father passed away. He started taking Hashish to cope up with the emotional loss and facing life hardships. "I used to smoke hashish on occasions and during evenings with friends, but later it became a daily habit. A single hashish cigarette makes you forget your heavy burdens," he added.

Syria is a country with geographical benefits for the cultivation and production of drugs. But now, more than ever, there has been a sudden rise in the drugs consumption (Hashish and Captagon). There is more than one reason for that. The most important reason being the ongoing Syrian revolution and internal conflicts in the country. The conflicts have certainly proven to be favorable for the drug dealers as it provided them a great opportunity to spread their drugs nationwide and especially to those who are under emotional and mental strain. Secondly, young children are the seeming to be the main target of them. They are forced to take drugs and then are used for beggary and prostitution, human trafficking. Those who have lost their beloved families in wars, adore these small pills of venom for a short period of false pleasure and content. All these different reasons initiate the stress and depressing thoughts in a person. Family is the basic institution that can perfectly provide the support required to get out of these miseries, but when family is the reason for these situations or when family fails to provide that much needed support,the person starts feeling anxious and while drowning in the sea of pity and anxiety, the high 
of drugs feels heavenly even if it is hoax and for a little period. This discussion is written on the basis of our observations and beliefs, with the help of articles and some general interviews. The result and conclusion are drawn accordingly to the discussion.

\section{RESULT:}

The main motive to conduct this research was to point out the neglects and problems from family that stresses out an individual to the point that it starts seeking comfort even if it is for a short amount of time with repercussions. To further make our point strong, some interviews were also conducted in which people were asked some certain questions regarding our research. All the answers were given according to their beliefs and observations.

Some of the reasons for an individual becoming a drug addict are the separation of their father in their childhood, paternal jobs, marital discord, death of parents or closed ones and the major cause is if a parent is drug addict. If even only one parent is drug addict, the chances are very high for the child to be interested and engaging in drug addiction.

To prove this statement further, an interview was conducted. When asked what is their opinion on the belief that a child of drug addicted parents is most likely to become a victim of this addiction too, this was their answer: According to the views of the responder, "children who experience dealing with a druggie and are used to watching an unconscious parent mostly hate the general idea of drugs. Because although their parent is high, but they are observing the situation of their intoxicated parent and the social and mental destruction that comes as a gift with the addition of these sort of drugs, they are mostly antagonistic towards drug usage. I myself use some of these substances that can be referred as drugs, but I'm certain that my family despise this action despite all their love for me." And according to the views of second responder, "It depends on the family dynamics, if the family is against drug usage, the children might end up hating on their parent and their actions. But on the other hand, and what mostly happens is, a child idolizes its parents, so when it sees them using drugs, it is most 
certain that the child will sometime in the future surely do it too. And most importantly, the thinking of the child is if my parents are doing it, then there must be no harm in it. The subject quoted a famous Urdu saying,' Charsika beta bhiCharsi hi hotahai'. The interview was ended with an example given by the subject," my cousin was generally opposed to the idea of cigarettes, but when eventually growing up he saw his father smoking cigarettes, it spurred something in him and now we seehim as a chain smoker." This interview shows the impact of a narcotic or addict parent on their child. Drug addiction is most common in allover the world not only Pakistan specially in children because of their family isolation, children hate their parents and they use drugs, and this maybe the fault of their parents because lack of attention might cause the child in involving such activities. Sometimes children may become a drug addict just to gain attention of their parents and relatives.

Some other reasons for an individual becoming a drug addict are the separation of their father in their childhood, paternal jobs, marital discord, death of parents or closed ones andthe major cause is if a parent is drug addict. If even only one parent is drug addict, the chances are very high for the child to be interested and engaging in drug addiction. The lack of communication can also be described as another major factor in steering an individual towards drug addiction. Man is a social animal and while socializing, thousands of thoughts penetrate a person's mind which can either pleasant or problematic. Families often neglect the importance of communication.

Parents are often up tied in this regard. They do not think it as a necessity to sit down and have some casual chats with their children just for the sake of it and might ask them about their problems or any issue Half of the stress can be released with simply just sharing the problem with them with closed onesand family. In the case of such families where there are no practices of sharing and communicating, the individual will try to find some other heart to disclose its miseries; they might get tangled into bad groups who lead them to using drugs as a temporary relief. 
These are not the only complications or lacking within or from the family that spurs an individual in initiating the venomous addictions. There are so many other factors within the family that might stress out an individual till the point that it starts taking feign satisfying drugs. The financial burden, responsibility of providing bread to the family, the struggles of finding job at an early age, the desire to produce more money in a short span, sometimes even through a shortcut, are mostly the reasons of hypertension of an individual. The mental stress needs to be relieved one way or another, and the most convenient way might come off as the intake of narcotics or drugs. Drugs are also used in a state of utter sadness, so in the state of melancholy because of the death of a parent or a family member, people ordinarily cherish the idea of striving timely happiness and the feeling of contentment allowed mainly from the high of drugs.

Another interview was conducted to an individual who had strong opinions on this ordeal. They had some strong observations as their friend, unfortunately, had to go through same crisis and now are in a rehabilitation centre. When a question 'what do you think, does families financial status contributes as one of the reason a person gets involved in drug addiction or not?' was asked to a individual, they responded:

According to the views of responder, "when a person's family status is financially weak, the person is under a lot of pressure. He needs job, money to buy necessities for daily life, money to pay bills, to feed the mouths that are waiting for him to bring something to eat, all the things basically add up to the availability of money. In Pakistan, it is not really easy to earn money except for begging. The stress that comes with the pressure of money earning is a lot, and the easiest way us Pakistanis think to reduce pressure off our minds is nicotine that is easily available in the form of cigarettes. And when a person starts smoking cigarettes, gradually it is not enough to satisfy his need and allow him the pleasure he is craving for. Then a person becomes chain smoker, starts taking different types of drugs and even sometimes alcohol. Sp yeah definitely the stress which comes with the financial problems is definitely one of the reasons why an individual decides to start taking drugs. 
I am not telling you a tale or something that is only written in books. This is my personal observation. There was a friend of mine whom father died at a very young age. He was maybe 14 or 15 years old and we were class mates. He had to drop his education and work somewhere to provide for his family. The stress this situation brought upon him was unbearable. The idea that taking drugs would solve all his problems was somehow stuck in his head and he started taking huge amount of drugs. Gradually, the addiction got worse and now he is in some rehabilitation center and working on his recovery."

So these are the result of ideas which we gained from the interviews or articles and websites. Role of family in drug addiction is a very important and this is an interesting issue now a days as the rate of drug addiction in teens especially is rising alarmingly. The basic problem is parents not being attentive towards the needs and actions of their children. Parents are the basic socializing and teaching agents of their children. If proper awareness, care, attention and the sternness necessary in this ordeal are not given to the child, the child may become a morphinist or a pill popper.

\section{CONCLUSION:}

Addictive behaviors are rather gravely and needs to be treated on multiple dimensions. Unfortunately, they are not considered crucial and the families are not ready to regard this problem. Only with the acceptance, this agonizing problem of the society can be saved. Families can be sometimes very harsh and dilapidated in their actions, and unknowingly and unintentionally, they push the individual towards the pernicious pavement of drug addiction that not only proves to be threat to their physical health, it also affects the mental health and cancerous diseases. Moreover, the life expectancy of drug addicts is rather low than those who are not addicted. The main inspiration to conduct this research was to point out the mistakes that families make rather inadvertently, but they prove to be disastrous for their children or another member not only in the short run but also in the long run. No nation can prosper until problems like these strive in their youth. The problem of drug addiction can be solved by family support, proper treatment through professional help or 
consultancy with rehabilitation centers. Over and above everything else, drug addiction should be taken as seriously as possible. As you endure through the various stages of treatment, remember what you are aiming for to make a better example of your life both for your own fulfillment as well as for the pleasure of those who love and adore you. Take the step towards recovery today and live to witness amazing changes in your life. 


\section{References:}

Barnard, M. (2006). Drug addiction and families. London Jessica Kingsley Publishers.

Das, J. K., Salam, R. A., Arshad, A., Finkelstein, Y., \& Bhutta, Z. A. (2016). Interventions for adolescent substance abuse: An Overview of systematic reviews. Journal of Adolescent Health, 59(4), S61-S75.

Foo, Y. C., Tam, C. L., \& Lee, T. H. (2012). Family factors and peer influence in drug abuse: a study in rehabilitation centre. International Journal of Collaborative Research on Internal Medicine \& Public Health, 4(3), 189.

Lalevee, T. (1985). Drugs and Dirty Money Finance the Assad Clan's Greater Syria. Exsicutive Intelligence Review. EIR 12(14). Retrieved From https://larouchepub.com/eiw/public/1985/eirv12n1419850409/eirv12n14-19850409_033-

drugs_and dirty money finance th.pdf

Marshall, J. (2012). The Lebanese connection: Corruption, civil war, and the international drug traffic. Stanford University Press. Retrieved from https://www.pdfdrive.com/the-lebanese-connection-corruption-civilwar-and-the-international-drug-traffic-e176242207.html

Matthew, K. J., Regmi, B., \& Lama, L. D. (2018). Role of Family in Addictive Disorders. International Journal of Psychosocial Rehabilitation. Vol 22 (1) 65, 75.

Mayo Foundation for Medical Education and Research. (2017, October 26) Drug addiction (substance use disorder) care at Mayo Clinic. Retrieved from https://www.mayoclinic.org/diseases-conditions/drugaddiction/symptoms-causes/syc-20365112

Miller, R. L. (2002).The Encyclopedia of addictive drugs. Greenwood Publishing Group. Retrieved from https://b-ok.cc/book/529441/1f4edc. 
Odeh, D., Jalil, M. A., Abu Zeid, O. (2018, November 29) Production, abuse and smuggling Drugs spreading in Syria, Enab Baladi Retrieved from (https://english.enabbaladi.net/archives/2018/11/production-abuseand-smuggling-drugs-spreading-in-syria

Sheff, D. \& Sheff, N. (2019). High: Everything You Want to Know About Drugs, Alcohol, and Addiction. HMH Books for Young Readers. Retrieved from https://b-ok.cc/book/3668009/4dc1ee.

Syria's Drug Control Director Accused of covering up for Traffickers (2019, August 26) Damascus: Asharq Al-Awsat. Retrieved from https://aawsat.com/english/home/article/1873281/syria\%E2\%80\%99sdrug-control-director-accused-covering-traffickers

The Global Initiative against Transnational Organised Crime (2016, November). The nexus of conflict and illicit drug trafficking: Syria and wider region. Retrieved https://globalinitiative.net/wpcontent/uploads/2016/10/The-nexus-of-conflict-and-illicit-drugtrafficking-Syria-and-the-wider-region.pdf. 